\title{
Increased prevalence of insecticide resistance in Anopheles coluzzii populations in the city of Yaoundé, Cameroon and influence on pyrethroid-only treated bed net efficacy
}

\author{
Roland Bamou ${ }^{1,2, *}$, Edmond Kopya ${ }^{2,3}$, Leslie Diane Nkahe ${ }^{2,3}$, Benjamin D. Menze ${ }^{4,5}$, Parfait Awono-Ambene ${ }^{2}$, \\ Timoléon Tchuinkam ${ }^{1}$, Flobert Njiokou ${ }^{3}$, Charles S. Wondji ${ }^{4,5}$, and Christophe Antonio-Nkondjio ${ }^{2,4, *}$ \\ ${ }^{1}$ Vector-Borne Diseases Laboratory of the Applied Biology and Ecology Research Unit (VBID-URBEA), Department of Animal \\ Biology, Faculty of Science of the University of Dschang, P.O. Box 067, Dschang, Cameroon \\ ${ }^{2}$ Laboratoire de Recherche sur le Paludisme, Organisation de Coordination pour la lutte contre les Endémies en Afrique Centrale \\ (OCEAC), B.P. 288 Yaoundé, Cameroon \\ ${ }^{3}$ Faculty of Sciences, University of Yaoundé I, P.O. Box 337, Yaoundé, Cameroon \\ ${ }^{4}$ Vector Biology, Liverpool School of Tropical Medicine, Pembroke Place, Liverpool L3 5QA, United Kingdom \\ ${ }^{5}$ Centre for Research in Infectious Disease (CRID), P.O. Box 13591, Yaoundé, Cameroon
}

Received 12 August 2020, Accepted 8 January 2021, Published online 2 February 2021

\begin{abstract}
In Cameroon, pyrethroid-only long-lasting insecticidal nets (LLINs) are still largely used for malaria control. The present study assessed the efficacy of such LLINs against a multiple-resistant population of the major malaria vector, Anopheles coluzzii, in the city of Yaoundé via a cone bioassay and release-recapture experimental hut trial. Susceptibility of field mosquitoes in Yaoundé to pyrethroids, DDT, carbamates and organophosphate insecticides was investigated using World Health Organization (WHO) bioassay tube tests. Mechanisms of insecticide resistance were characterised molecularly. Efficacy of unwashed PermaNet ${ }^{\circledR} 2.0$ was evaluated against untreated control nets using a resistant colonised strain of An. coluzzii. Mortality, exophily and blood feeding inhibition were estimated. Field collected An. coluzzii displayed high resistance with mortality rates of $3.5 \%$ for propoxur $(0.1 \%)$, $4.16 \%$ for DDT $(4 \%), 26.9 \%$ for permethrin $(0.75 \%), 50.8 \%$ for deltamethrin $(0.05 \%)$, and $80 \%$ for bendiocarb $(0.1 \%)$. High frequency of the $1014 \mathrm{~F}$ west-Africa $k d r$ allele was recorded in addition to the overexpression of several detoxification genes, such as Cyp6P3, Cyp6M2, Cyp9K1, Cyp6P4 Cyp6Z1 and GSTe2. A low mortality rate (23.2\%) and high blood feeding inhibition rate $(65 \%)$ were observed when resistant An. coluzzii were exposed to unwashed PermaNet $^{\circledR} 2.0$ net compared to control untreated net $(p<0.001)$. Furthermore, low personal protection $(52.4 \%)$ was observed with the resistant strain, indicating reduction of efficacy. The study highlights the loss of efficacy of pyrethroid-only nets against mosquitoes exhibiting high insecticide resistance and suggests a switch to new generation bed nets to improve control of malaria vector populations in Yaoundé.
\end{abstract}

Key words: An. coluzzii, Insecticide Resistance, Susceptibility, LLINs, Experimental-hut, Bioassay, Cameroon.

Résumé - Augmentation de la prévalence de la résistance aux insecticides chez les populations d'Anopheles coluzzii de la ville de Yaoundé (Cameroun) et influence sur l'efficacité des moustiquaires traitées uniquement aux pyréthrinoïdes. Au Cameroun, moustiquaires insecticides de longue durée (MILDA) contenant uniquement des pyréthrinoïdes sont encore largement utilisées pour lutter contre le paludisme. La présente étude a évalué l'efficacité de ces MILDA contre une population multi-résistante du principal vecteur du paludisme, Anopheles coluzzii, de la ville de Yaoundé, en utilisant un test de bio-efficacité et la technique de lâchage-recapture dans des cases-pièges expérimentales. La sensibilité des moustiques collectés sur le terrain à Yaoundé aux pyréthrinoïdes, au DDT, aux carbamates et aux insecticides organophosphorés a été étudiée à l'aide de tests en tube de bio-essai de l'Organisation Mondiale de la Santé (OMS). Les mécanismes de résistance aux insecticides ont été caractérisés au niveau moléculaire. L'efficacité du PermaNet ${ }^{\circledR} 2.0$ non lavé a été évaluée par rapport à une moustiquaire contrôle non traitée en utilisant une souche colonisée résistante d'An. coluzzii. La mortalité, le taux d'inhibition de gorgement ont été estimées. Les An. coluzzii collectés sur le terrain ont montré une résistance élevée avec des taux de mortalité de 3,5\% pour le propoxur $(0,1 \%), 4,16 \%$ pour le DDT $(4 \%), 26,9 \%$ pour la perméthrine $(0,75 \%), 50,8 \%$ pour la deltaméthrine $(0,05 \%)$ et $80 \%$ pour le bendiocarbe $(0,1 \%)$. Une fréquence élevée de l'allèle $1014 \mathrm{~F}$ kdr ouest-africain a été enregistrée en plus

*Corresponding authors: bamou20ll@gmail.com; antonio_nk@yahoo.fr

This is an Open Access article distributed under the terms of the Creative Commons Attribution License (https://creativecommons.org/licenses/by/4.0), which permits unrestricted use, distribution, and reproduction in any medium, provided the original work is properly cited. 
de la surexpression de plusieurs gènes de détoxification tels que Cyp6P3, Cyp6M2, Cyp9K1, Cyp6P4 Cyp6Z1 et GSTe2. Un faible taux de mortalité $(23,2 \%)$ et un taux élevé d'inhibition de gorgement $(65 \%)$ ont été observés lorsque les An. coluzzii ont été exposés à une moustiquaire PermaNet ${ }^{\circledR} 2.0$ non lavée par rapport à une moustiquaire témoin non traitée $(p<0,001)$. De plus, une faible protection individuelle $(52,4 \%)$ a été observée avec la souche résistante indiquant une réduction de leur efficacité. L'étude met en évidence la perte d'efficacité des moustiquaires aux pyréthrinoïdes contre les moustiques présentant une résistance élevée aux insecticides et suggère le remplacement de ces moustiquaires par des moustiquaires de nouvelle génération pour améliorer le contrôle des populations de vecteurs du paludisme à Yaoundé.

\section{Introduction}

Malaria is a major cause of morbidity and mortality in Sub-Saharan Africa, and in 2019 the disease was responsible for over 409,000 deaths and 229 million cases [60]. In the absence of a vaccine, disease prevention relies mostly on the use of vector control measures with insecticide-based methods such as long-lasting insecticidal nets (LLINs) and indoor residual spraying (IRS) as the main interventions [13, 37, 56]. According to the World Health Organization (WHO), close to 1.9 billion mosquito nets have been distributed across Africa since 2000 [59]. The massive scale-up of insecticide treated nets (ITNs) and LLINs between 2000 and 2015 across the world is considered to have adverted 630 million malaria cases [13]. However since 2015, increases in malaria incidence and disease transmission have been reported in many parts of the world [60], suggesting a decrease in the efficacy of LLINs and IRS used until now as core interventions $[6,34,46]$. Several factors could be responsible for the poor performance of control measures, including low usage rates of bed nets [31], changes in the biting and resting behaviour of mosquitoes [9, 18, 25, 31], and the rapid expansion of insecticide resistance in vector populations $[4,9,10,18,33,53]$. The rapid expansion of insecticide resistance resulting from the massive use of insecticides in both agriculture and public health, is considered a major threat limiting the performance of current control tools [41, 62]. Several mechanisms such as target site resistance, notably knockdown resistance $(k d r)$ [4, 9, 10], modified acetylcholinesterase Ace- $1^{\mathrm{R}}[10,19]$, the overexpression of detoxification genes $[10,19,47,53,61]$, or cuticular resistance $[7,8$, $10,50,63]$ have been reported to induce resistance to insecticides in vector populations. However, despite the diversity of resistance mechanisms and the increasing prevalence of insecticide resistance in vector populations, there is still not enough evidence from the field on how insecticide resistance affects the efficacy of treated nets. Recent studies on Anopheles funestus indicated that the expansion of pyrethroid resistance mediated by metabolic mechanisms such as monoxygenase P450 [32, 55] and glutathione s-transferase GST [30] was impacting the efficacy of nets.

In Cameroon, malaria remains a major public health concern in both urban and rural settings [9, 18]. Mosquitoes from the Anopheles gambiae complex are the main vectors of malaria across the country [2]. Studies conducted so far have suggested rapid expansion of insecticide resistance in these vector populations and in An. funestus [4, 5]. Despite the rapid expansion of insecticide resistance in vector populations, and the availability of new generation nets that are more efficient against insecticide resistant mosquitoes species, pyrethroid-only bed nets are still largely used by the population to minimize the malaria burden [43]. Yet there are still not enough data on the efficacy of pyrethroid-only treated nets against insecticide-resistant Anopheles gambiae s.l. populations in Cameroon, particularly in the city of Yaounde $[3-5,15,30]$. Experimental hut trials are commonly used to assess the efficacy of insecticide-treated bed nets [12, 34, 38, 58]. Many bed net efficacy studies in experimental hut trials have been conducted using free-entering mosquitoes [6, 12, 27, 28, 30, 38, 54]. Others used releaserecapture mosquitoes [17, 45]. The present study was conducted to assess the efficacy of pyrethroid-only LLINs against a multi-resistant Anopheles coluzzii population in the city of Yaoundé using both an experimental hut trial and cone bioassay.

\section{Materials and methods}

\section{Ethics approval and consent to participate}

The study was conducted under ethics clearance No. 2016/ 01/685/CE/CNERSH/SP issued by the Cameroon National Ethics (CNE) Committee for Research on Human Health.

\section{Mosquito colonies}

Mosquitoes used for the study included two susceptible laboratory colonies (An. coluzzii Ngousso and An. gambiae Kisumu), a resistant colony (An. coluzzii) maintained at the OCEAC (Organisation de Coordination pour la lutte Contre les Endémies en Afrique Centrale) Malaria Research insectary, and wild An. coluzzii reared from larvae collected in Yaoundé $\left(3^{\circ} 520 \mathrm{~N} ; 11^{\circ} 310 \mathrm{E}\right)$. The field population of An. coluzzii was constituted after collecting mosquitoes (in December 2017) in different habitats, including temporary water collections, puddles and semi-permanent sites in order to capture the genetic variability of the species in Yaoundé. The different groups of mosquitoes (susceptible strains, resistant colony, and field collected An. coluzzii) were used for insecticide bioassays involving the WHO tube test and cone test.

\section{Establishment of a resistant laboratory colony}

Anopheline larvae, collected in standing water collections as described above, were pooled and reared in the laboratory at optimal temperature and humidity $\left(28-30{ }^{\circ} \mathrm{C}\right.$ and $70-80 \%$ relative humidity). Larvae were reared in trays of $500 \mathrm{~cm}^{2}$, each tray containing 50-100 larvae and were fed using Tetramin ${ }^{\circledR}$ 
babyfish food. After emergence, males were separated from females, then each group was exposed to deltamethrin $0.05 \%$, according to WHO guidelines [58]. Mosquitoes surviving $24 \mathrm{~h}$ after exposure were pooled for mating and subsequent egg-laying. A resistant colony was established by regular selection of mosquitoes, exposing 3-5 day-old unfed females and males to $0.05 \%$ deltamethrin for three generations.

\section{Insecticide susceptibility test}

Adult female An. gambiae s.l. mosquitoes, obtained from field-collected larvae were exposed to insecticide impregnated papers alongside the An. gambiae Kisumu and An. coluzzii Ngousso susceptible strains and the An. coluzzii resistant colony, following WHO guidelines [58]. Mosquitoes were exposed to the following insecticide concentrations: deltamethrin $0.05 \%$, permethrin $0.75 \%$, DDT $4 \%$, bendiocarb $0.1 \%$, propoxur $0.1 \%$, malathion $5 \%$ and fenitrothion $1 \%$. In addition, the synergistic effect of piperonyl butoxide (PBO) on the mortality of wild collected An. gambiae s.l. was also tested using the WHO tube bioassay to assess possible implication of monoxygenase-based metabolic resistance (P450). The susceptible strains An. gambiae Kisumu and An. coluzzii Ngousso were used to assess the efficacy of the impregnated papers. Anopheles gambiae s.l. females aged 3-5 days, were introduced in batches of 20-25 mosquitoes per tube and exposed to insecticide-impregnated papers. After $1 \mathrm{~h}$ exposure, mosquitoes were transferred to observation tubes and then fed with a $10 \%$ sugar solution. The number of dead mosquitoes was recorded after $24 \mathrm{~h}$ post-exposure. During each bioassay, a batch of mosquitoes used as a control were exposed to untreated papers. For tests with PBO, batches of 20-25 individuals were first placed in a tube with PBO paper for $1 \mathrm{~h}$ before being exposed to deltamethrin $0.05 \%$ or permethrin $0.75 \%$. For each insecticide, four replicates and two controls (untreated paper) were run. Bioassays on susceptible laboratoryreared mosquitoes, An. gambiae Kisumu and An, coluzzii Ngousso strains were run before bioassays on wild collected An. gambiae s.l. All the impregnated papers used for the study were obtained from the Universiti Sains Malaysia and kept at $4{ }^{\circ} \mathrm{C}$ before and after each test.

\section{WHO cone test}

Mosquitoes were also exposed using WHO cone bioassays to check the efficacy of PermaNet ${ }^{\circledR} 2.0$ treated nets. The susceptible strains (Kisumu and Ngousso), and the selected colony of resistant An. coluzzii females were used. A number of mosquitoes varying from 5 to 10 aged 3-5 days were released in a cone fitted with a treated net $\left(\right.$ PermaNet $^{\circledR}$ 2.0) and exposed for $3 \mathrm{~min}$ according to WHO guidelines [58]. Similar bioassays were conducted with untreated nets used as a control. Tests were conducted with the ceiling and the sides of the nets. After exposure, mosquitoes were transferred to cups and allowed to feed on cotton wool soaked with a $10 \%$ sugar solution then left for observation for $24 \mathrm{~h}$. At the end of this period, the number of dead and surviving mosquitoes was recorded.
Anopheles gambiae s.l. identification and characterisation of insecticide resistance

A sample of mosquitoes from the resistant strain was used for species identification and $k d r$ mutation detection, while field collected Anopheles spp. were used for both target site mutation and metabolic-based insecticide resistance gene detection (gene expression analysis). For An. gambiae s.l. identification, the protocol described by Santolamazza et al. [49] was used. Target site mutations (L1014F, L1014S and G119S) were assessed using the protocol described by Bass et al. [11], while gene expression analysis was performed using newly developed quantitative reverse transcription-real-time PCR (qRT-PCR) 3-plex assays, as described in Bamou et al. [10]. Genes analysed included Cyp6m2, Сур6p3, Сур6p4, Сур6p1, Cyp9k1, Cyp4g16 and GSTE2. For normalisation purposes, the RPS7 gene was used [29].

\section{Bed nets used}

The treated bed nets used for cone bioassays and the experimental hut trial were PermaNet ${ }^{\circledR} 2.0$ bought from the market. The nets are $100 \%$ polyester coated with $1.8 \mathrm{~g} / \mathrm{kg}$ of deltamethrin. The mosquito nets were intentionally holed according to World Health Organization Pesticide Evaluation Scheme (WHOPES) directives [36, 57] in the middle part, on a surface representing approximately $0.8 \%$ of the total surface. This was to mimic the real situation of LLINs in villages where LLINs have holes due to frequent use and to see whether the net was just a physical barrier and whether the insecticide was able to prevent blood feeding, even if the net had holes. Six holes of $4 \mathrm{~cm}^{2}(2 \mathrm{~cm} \times 2 \mathrm{~cm})$ were made in each net (unwashed PermaNet ${ }^{\circledR} 2.0$ and untreated nets), 2 holes in each of the long-side panels, and one hole at each end (i.e. head and foot-side panels).

\section{Assessment of hut lethality}

Prior to the experimental hut trial, a series of bioassays were conducted to assess the lethal effect of huts using susceptible mosquitoes (Kisumu and Ngousso). Adult mosquitoes were exposed to various surfaces in the huts including the ceiling, floor, doors, walls and screening-mesh of the veranda. Bioassays were performed using WHO testing cones attached to surfaces with masking tape. Ten 3-5-day-old females of the An. gambiae Kisumu and An coluzzii (Ngousso) strains were put into each cone for $30 \mathrm{~min}$ [1]. After exposure, they were removed from the cones and put into plastic cups covered with untreated mosquito net and given access to $10 \%$ glucose solution, and mortality was recorded after $24 \mathrm{~h}$.

\section{Release-recapture experimental hut trials}

Five West African style experimental huts with a veranda, where mosquitos are allowed to enter freely, were used for the study, with slight modifications. The station is located in Mibelon and further details can be found in Menze et al. [29]. Window slits were closed, preventing wild mosquitoes from entering and released mosquitoes from escaping [17, 45]. 
The protocol used was approved by the National Ethics Committee (No. 2016/01/685/CE/CNERSH/SP), and each volunteer participating in the study signed the informed consent form after explanation of the objective of the study and risks associated with their participation. In addition, volunteers received medical care in case of illness during the entire duration of the study. After recruitment, volunteers were trained before the trials and only five collectors with similar body size and good skills were retained for the study. Every night, four volunteers slept each under a treated net (unwashed PermaNet ${ }^{\circledR}$ 2.0) in a hut, and one volunteer was placed under an untreated net used as a control from $8 \mathrm{pm}$ to $6 \mathrm{am}$. To prevent volunteers leaving experimental huts during the night, drinking water was provided and a urinal receptacle made available. When volunteers were under their net, a batch of 100 pyrethroid-resistant mosquitoes were introduced into the hut and the catches were made in the morning at $6 \mathrm{am}$. Mosquitoes were collected individually in tubes and then kept in bags labelled according to the place of capture/collection or compartment of the hut: inside the mosquito net, in the hut (outside the mosquito nets, on the walls and ceiling), and in the veranda-trap. The huts were checked each afternoon before the catches. To create a contrast between the ground and mosquitoes, a white plastic tissue was placed on the ground and replaced with a clean one each day before the experiment. During each mosquito release session, the sleepers carried out circular permutation between the huts, in order to avoid bias due to the effect of preferential attraction that they could offer. The status of mosquitoes collected each morning was registered (unfed, blood-fed, dead, alive) as reported elsewhere [48], and those alive were put in small paper cups with access to $10 \%$ glucose solution, with $24 \mathrm{~h}$ observations and recording for any cases of possible delayed mortality. The mosquitoes collected were morphologically identified using a binocular microscope [21, 22], to verify the intrusion of other species into the huts during the day when the huts were cleaned.

\section{Outcomes measures}

The following outcomes were measured to assess the efficacy of the unwashed PermaNet ${ }^{\circledR} 2.0$ nets in experimental huts:

(i) Exophily (Excito-repellency): the proportion of mosquitoes found exited in the veranda trap. Exophily $(\%)=100 \times(E v / E t)$ where $E v$ is the total number of mosquitoes found in the veranda and $E t$ is the total number of both inside the hut and veranda.

(ii) Blood feeding rate (BFR): this rate was calculated as follows: Blood feeding rate $=(N$ mosquitoes fed $) \times 100 /$ total $N$ mosquitoes. Where " $N$ mosquitoes fed" was the number of mosquitoes fed, and "total $N$ mosquitoes" was the total number of mosquitoes collected.

(iii) Blood feeding inhibition (BFI): the reduction in blood feeding in comparison with the control hut. Blood feeding inhibition is an indicator of personal protection (PP). More precisely, the personal protection effect of each bed net is the reduction of blood feeding percentage induced by the net when compared to the control. The protective effect of each bed net can be calculated as follows: Personal protection $(\%)=100 \times(B u-B t) / B u$, where $\mathrm{Bu}$ is the total number of blood-fed mosquitoes in the huts with untreated nets, and $B t$ is the total number of blood-fed mosquitoes in the huts with treated nets [57].

(iv) Immediate and delayed mortality: the proportion of mosquitoes entering the hut that are found dead in the morning (immediate mortality) or after being caught alive and held for $24 \mathrm{~h}$ with access to sugar solution (delay mortality). In this study, we focused on the overall mortality calculated as follows: Mortality $(\%)=100 \times(M t / M T)$ where $M t$ is the total number of mosquitoes found dead in the hut, and $M T$ is the total number of mosquitoes collected in the hut [57].

\section{Statistical analysis}

Differences in proportional outcome variables (mortality, blood feeding inhibition, and exophily) between treatment (unwashed PermaNet ${ }^{\circledR} 2.0$ ) and control (untreated net) were analysed using logistic regression, after adjusting for the effect of the sleeper. The number of mosquitoes entering the nets, the numbers succeeding in feeding, and the numbers killed were analysed using negative binomial regression with adjustments for sleepers. Insecticide resistance results from bioassays were interpreted following WHO guidelines [58]. Chi square tests were used to compare mortality between mosquitoes exposed to pyrethroids and the pyrethroids-PBO combination. Calculation of fold-change, 95\% confidence intervals, and statistical significance were performed using the Pfaffl method [40]. These analyses were done on STATA version 11 .

\section{Results \\ Insecticide susceptibility status of An. gambiae populations}

Field An. gambiae s.l. females were found to be resistant to DDT, pyrethroids and carbamates and susceptible to organophosphates (Table 1). The mortality rate was $50.8 \%$ for deltamethrin, $26.9 \%$ for permethrin, $4.16 \%$ for DDT, $3.33 \%$ for propoxur, and $85 \%$ for bendiocarb (Table 1). Female An. gambiae s.l. pre-exposed to PBO showed an increase in susceptibility to both permethrin (with the mortality rate increasing from $26.9 \%$ to $35 \%)(p<0.0001)$ and deltamethrin (with the mortality rate increasing from $50.8 \%$ to $72 \%$ ) ( $p<0.0001)$. The resistant An. coluzzii population exhibited a mortality rate of $35 \%(n=100 ; 95 \%$ CI: $24.37-48.67)$ and $8 \%(n=100 ; 95 \%$ CI: $3.45-15.46)$ for deltamethrin and permethrin, respectively (Table 1 ).

\section{Molecular characterisation of insecticide resistance}

A subsample of 100 An. gambiae s.l. females from the field and the resistant strain were used for species identification and insecticide resistance characterisation. All mosquitoes screened were An. coluzzii. For target site mutation, only the L1014F 
Table 1. Mortality rate of Anopheles gambiae s.l. from Yaoundé exposed to certain insecticides.

\begin{tabular}{|c|c|c|c|c|c|c|c|c|}
\hline & \multicolumn{2}{|c|}{$\begin{array}{l}\text { An. coluzzii resistant } \\
\text { strain }\end{array}$} & \multicolumn{2}{|c|}{$\begin{array}{l}\text { Field An. gambiae } \\
\text { s.l. }\end{array}$} & \multicolumn{2}{|c|}{$\begin{array}{l}\text { An. coluzzii Ngousso } \\
\text { strain }\end{array}$} & \multicolumn{2}{|c|}{$\begin{array}{l}\text { An. gambiae Kisumu } \\
\text { strain }\end{array}$} \\
\hline & $N$ & $\begin{array}{l}\text { \%Mortality } \\
{[95 \% \mathrm{CI}]}\end{array}$ & $N$ & $\begin{array}{l}\text { \%Mortality } \\
{[95 \% \mathrm{CI}]}\end{array}$ & $N$ & $\begin{array}{c}\text { \%Mortality } \\
{[95 \% \mathrm{CI}]}\end{array}$ & $N$ & $\begin{array}{l}\text { \%Mortality } \\
{[95 \% \mathrm{CI}]}\end{array}$ \\
\hline Permethrin & 100 & $8[3.5-15.8]$ & 156 & $26.9[19.4-36.4]$ & 100 & $100[81.4-121.6]$ & 100 & $100[81.4-121.6]$ \\
\hline Deltamethrin & 100 & $35[24.4-48.7]$ & 258 & $50.8[42.5-60.3]$ & 100 & $100[81.4-121.6]$ & 100 & $100[81.4-121.6]$ \\
\hline DDT & - & - & 120 & 4.16 [1.4 - 9.7] & 100 & 98 [79.6 - 119.4] & 100 & 99 [80.5 - 120] \\
\hline Propoxur & - & - & 120 & $3.33[0.9-8.5]$ & 100 & $100[81.4-121.6]$ & 100 & $100[81.4-121.6]$ \\
\hline Bendiocarb & & - & 100 & 86 [68.8 - 106.2] & 100 & $100[81.4-121.6]$ & 100 & $100[81.4-121.6]$ \\
\hline Malathion & - & - & 120 & $100[82.9-119.6]$ & 100 & $100[81.4-121.6]$ & 100 & $100[81.4-121.6]$ \\
\hline Fenitrothion & - & - & 120 & $100[82.9-119.6]$ & & - & & - \\
\hline PBO Deltamethrin & - & - & 120 & $71.66[57.3-88.5]$ & & - & & - \\
\hline PBO Permethrin & - & - & 100 & $35.0[24.4-48.7]$ & & - & & - \\
\hline
\end{tabular}

$N$ : number of mosquitoes tested; $95 \%$ CI: $95 \%$ confidence interval.

Table 2. Gene expression analysis of field collected Anopheles coluzzii from Yaoundé compared to the susceptible Ngousso (NG) and Kisumu (KIS) strains.

\begin{tabular}{lcccccccc}
\hline & \multicolumn{7}{c}{ Fold changes $(95 \%$ CI) } \\
\cline { 2 - 8 } & CYP6P3 & CYP6M2 & CYP9K1 & CYP6P4 & CYP6Z1 & GSTE2 & CYP6P1 & CYP4G16 \\
\hline vs. KIS & $\mathbf{4 . 2 2}$ & $\mathbf{4 . 5 0}$ & $\mathbf{7 . 3 0}^{*}$ & $\mathbf{3 . 8 0}^{*}$ & $\mathbf{3 . 4 0} *$ & $\mathbf{2 . 5 5}$ & 0.85 & $\mathbf{1 . 7 5}$ \\
& $(2.63-6.96)$ & $(2.93-6.10)$ & $(4.03-19.5)$ & $(2.56-5.09)$ & $(2.36-4.93)$ & $(1.99-3.12)$ & $(0.71-0.97)$ & $(1.20-3.76)$ \\
vs. NG & 1.18 & $\mathbf{2 . 7 5}^{*}$ & $\mathbf{2 . 8}^{*}$ & $\mathbf{2 . 9 9 *}$ & $\mathbf{2 . 5 2 *}$ & 0.71 & 0.45 & 1.21 \\
& $(0.80-1.78)$ & $(1.73-3.75)$ & $(1.76-5.71)$ & $(1.93-4.17)$ & $(1.64-3.42)$ & $(0.56-0.87)$ & $(0.36-0.56)$ & $(0.92-1.55)$ \\
\hline
\end{tabular}

Bold letters indicate statistically significant upregulation.

Asterisks indicate consistent upregulation compared to both susceptible strains $(p<0.05)$.

allele (West Africa Knockdown resistance allele), in both the homozygote $(n=98)$ and heterozygote state $(n=2)$, was detected. The $k d r$ allele frequency in the resistant colony was $99 \%$.

The expression profiles of eight genes implicated in insecticide resistance were analysed in the field collected mosquitoes from Yaoundé. All genes screened except Cyp6pl showed an overexpression profile compared to susceptible mosquitoes (Table 2). The highest overexpression was seen for gene Cyp6m2, with a fold change of 4.5. Other highly overexpressed genes also included Cyp9k1, Cyp6p3 Cyp6z1, and Cyp4g16.

\section{Cone bioassays with PermaNet ${ }^{\circledR} 2.0$ nets}

Efficacy of the deltamethrin-coated net (unwashed PermaNet ${ }^{\circledR}$ 2.0) was also evaluated using the resistant colony of An. coluzzii. For these tests, 269 females were exposed to PermaNet ${ }^{\circledR} 2.0$ nets, while 40 females were exposed to untreated nets (control). An average mortality rate of $44.24 \%$ was recorded after exposing mosquitoes to PermaNet ${ }^{\circledR} 2.0$ nets. For the controls, a mortality rate of $5 \%(n=40$; CI: $0.24-7.22)$ after $24 \mathrm{~h}$ observation was recorded (Table 3 ).

\section{Assessment of experimental hut lethality}

Baseline analysis using WHO cone bioassays was conducted on various areas of the hut, including doors, walls, veranda
Table 3. Knockdown and mortality of different Anopheles gambiae s.l. colonies used for cone bioassays.

\begin{tabular}{|c|c|c|c|c|}
\hline & \multicolumn{2}{|c|}{ Control } & \multicolumn{2}{|c|}{ PermaNet $^{(\mathbb{B}} 2.0$} \\
\hline & $N$ & $\%$ & $N$ & $\%$ \\
\hline An. coluzzii Ngousso strain & 60 & & 60 & \\
\hline Mortality after $24 \mathrm{~h}$ observation & 60 & 0 & 60 & 100 \\
\hline Knockdown at $60 \min (\%)$ & 60 & 0 & 60 & 100 \\
\hline An. gambiae Kisumu strain & 60 & & 60 & \\
\hline Mortality after $24 \mathrm{~h}$ observation & 60 & 0 & 60 & 100 \\
\hline Knockdown at $60 \min (\%)$ & 60 & 0 & 60 & 100 \\
\hline An. coluzzii Resistant strain & 40 & & 269 & \\
\hline Mortality after $24 \mathrm{~h}$ observation & 2 & 5 & 119 & 44.24 \\
\hline Knockdown at $60 \min (\%)$ & 1 & 2.5 & 175 & 65.05 \\
\hline
\end{tabular}

$N$ : number of mosquitoes tested (in bold) or dead (without bold).

screening-mesh, ceiling, and floor. About 10 mosquitoes were exposed per hut area (50 mosquitoes per hut). The analysis revealed that hut usage in this study had no lethality on the susceptible Kisumu and Ngousso strains. Very low mortality was observed in all huts, with mortality varying from $0 \%$ to $4 \%$, and with average mortality of $<2 \%$ per hut.

\section{Experimental hut trials}

A total of 4900 resistant An. coluzzii females were released in test huts over 8 consecutive days; 3666 were recaptured, representing a recapture rate of $74.8 \%$. 
Table 4. Evaluation of behavioural response of resistant Anopheles gambiae s.l. population exposed to PermaNet ${ }^{\circledR} 2.0$ nets.

\begin{tabular}{|c|c|c|c|}
\hline & Control & PermaNet $^{\circledR} 2.0$ & $p$-value \\
\hline Number of released females & 900 & 4000 & \\
\hline Number of recaptured females & 699 & 2967 & \\
\hline Recapture rate $(\%)$ & 77.67 & 74.17 & \\
\hline Number collected in room & 291 & 1124 & \\
\hline Number collected in veranda & 316 & 1709 & \\
\hline Collected in net $(\%)$ & $92(13.2)$ & $134(4.5)$ & \\
\hline Exophily (\%) $[95 \% \mathrm{CI}]$ & $45.2[41.52-48.90]$ & $57.6[55.82-59.38]$ & $<0.0001$ \\
\hline Induced exophily (\%) & & 22.62 & \\
\hline Number Blood-fed & 98 & 149 & \\
\hline Blood feeding rate $(\%)[95 \% \mathrm{CI}]$ & $14[11.45-16.59]$ & $5[4.24-5.81]$ & $<0.0001$ \\
\hline Blood feeding inhibition $(\%)$ & & 64.18 & \\
\hline Mortality of blood fed mosquitoes (\%) & $8(8.2)$ & $40(26.8)$ & $<0.0001$ \\
\hline Number dead & 116 & 687 & \\
\hline Overall mortality rate $(\%)[95 \% \mathrm{CI}]$ & $16.6[13.84-19.35]$ & $23.2[21.64-24.67]$ & $<0.0001$ \\
\hline Corrected mortality & & 7.82 & \\
\hline
\end{tabular}

\section{Exophily}

Relative to the untreated control net, the proportion of mosquitoes exiting to verandas was significantly higher in huts with unwashed PermaNet ${ }^{\circledR} 2.0$ nets $(p<0.0001)$. In the control hut, a $45.2 \%$ (316/699) exophily rate was recorded, whereas in huts with PermaNet ${ }^{\circledR} 2.0$ nets an exophily rate of $57.6 \%$ was found.

\section{Blood feeding rate}

Blood feeding rate was also significantly higher in the control compared to the test huts $(p<0.001)$. In the control hut, $14 \%$ of females (98) were blood-fed, while in test huts only $5 \%$ of mosquitoes were able to blood feed (149/2967). Unwashed PermaNet ${ }^{\circledR} 2.0$ nets inhibited blood feeding relative to the control at a frequency of $64.18 \%$ (Table 4).

\section{Mortality rate}

Immediate mortality varied significantly from $6.3 \%$ for control huts to $14.2 \%$ for test huts. Immediate mortality induced by PermaNet ${ }^{\circledR} 2.0$ nets on the resistant An. coluzzii population was $7.84 \%$. A total of 116 An. coluzzii were found dead after $24 \mathrm{~h}$ in the control hut, corresponding to a mortality rate of $16.6 \%$. In the test huts, a delayed mortality rate of $23.2 \%$ $(655 / 2967)$ was observed. The mortality in the test huts was significantly different from that of the control huts $(p<0.001)$. Of the 116 dead An. coluzzii collected from control huts, 8 (8.2\%) were blood-fed, while in test huts with PermaNet ${ }^{\circledR} 2.0$ nets, of the 687 dead mosquitoes collected, 40 (1.3\%) were blood-fed. The delayed mortality induced by the PermaNet ${ }^{\circledR}$ nets was $8.86 \%$ (Table 4).

\section{Chemical barrier}

In the control hut, 92 mosquitoes $(13.2 \%)$ were collected inside the mosquito net. In the test huts with PermaNet ${ }^{\circledR} 2.0$ nets, 134/2967 mosquitoes (4.5\%) were collected inside the nets. PermaNet ${ }^{\circledR} 2.0$ nets were found to significantly decrease
Table 5. Personal and community protection confered by Perma$\mathrm{Net}^{\circledR} 2.0$ nets when exposed to a resistant Anopheles coluzzii population.

\begin{tabular}{lcc}
\hline & Control $(u)$ & PermaNet 2.0 $(t)$ \\
\hline Caught mosquitoes $(E)$ & 699 & 2967 \\
Blood-fed $(B)$ & 98 & 149 \\
Personal protection* $(\%)$ & & $\mathbf{5 2 . 0 4}$ \\
Overall mortality $(D)$ & 116 & 687 \\
Mass protection** $(\%)$ & & $\mathbf{8 1 . 6 9}$ \\
\hline
\end{tabular}

* $100 \times(B u-B t) / B u$;

*** $100 \times(D t-D u) / E u$ where " $B u$ " is the total number of blood-fed mosquitoes in the huts with untreated nets, and " $B t$ " is the total number of blood-fed mosquitoes in the huts with treated nets. " $D t$ " is the number of dead mosquitoes in huts with treated nets, and " $D u$ " the number of dead mosquitoes in the control hut.

the rate of mosquitoes entering into the impregnated mosquito nets $(p<0.001)$.

\section{Personal and community protection}

PermaNet ${ }^{\circledR} 2.0$ nets were found to induce a personal protection rate of $52.04 \%$ and a community protection rate of $81.69 \%$, as shown in Table 5.

\section{Discussion}

Several new-generation nets have been prequalified by the WHO for use in malaria control and elimination. However, the WHO still recommends the use of prequalified pyrethroid-only LLINs as a core intervention in all malaria-endemic settings [60]. Pyrethroid-PBO nets prequalified by WHO are conditionally recommended for deployment where the principal malaria vector exhibits pyrethroid resistance conferred at least in part by a monooxygenase-based metabolic resistance mechanism [60]. In Cameroon, despite the rapid expansion of insecticide resistance in vector populations, pyrethroid-only 
LLINs are still largely used by the population for malaria prevention because they are the only ones distributed during mass distribution campaigns [43]. The present study was conducted to assess the efficacy of PermaNet ${ }^{\circledR} 2.0$ nets against a multiple insecticide-resistant An. coluzzii strain originating from the city of Yaoundé. Mosquito populations here were reported to express high resistance to DDT, pyrethroids, and carbamates, with resistance mechanisms including the $k d r$ allele (West and East $k d r$ ), and overexpression of detoxification genes such as Cyp6m2, Cyp6p3, Cyp6z2 Cyp9k1, Cyp6z1, and Cyp4g16 [3-5, 10]. Efficacy tests conducted with unwashed PermaNet ${ }^{\circledR} 2.0$ nets suggested low personal protection provided by these nets against resistant An. coluzzii populations in the city of Yaoundé. The mortality rate induced by PermaNet ${ }^{\circledR}$ 2.0 nets during the present study was far lower compared to previous studies [27]. The low mortality rate recorded during this study could be consistent with the high frequency of $k d r$ alleles and metabolic mechanisms expressed by mosquito populations in the city of Yaoundé $[4,5,10]$. In Benin, the mortality induced by pyrethroid-only bed nets was found to be $30 \%$ in an area with high pyrethroid resistant An. gambiae populations, whereas it was about $98 \%$ in areas with susceptible populations [34]. Nonetheless, continued efficacy of pyrethroidonly treated nets in areas with moderate resistance levels have been reported in many parts of the African continent [15, 17, 20, 26, 27]. Studies conducted so far across Africa, indicated high efficiency of new classes of nets combining the synergist PBO with pyrethroid against resistant mosquito populations compared to pyrethroid-only nets. In Cote d'Ivoire, higher mortality rates were recorded when resistant An. gambiae populations were exposed to alpha-cypermethrin $+\mathrm{PBO}$ mixture LLINs compared to standard LLINs [38]. In Burkina Faso, high efficiency against resistant An. gambiae populations was recorded with PBO-based nets (DawaPlus 3.0 and DawaPlus 4.0) [12]. A recent hut trial conducted in Cameroon using both PermaNet ${ }^{\circledR}$ 2.0, Olyset Plus and PermaNet ${ }^{\circledR} 3.0$ nets indicated that PBO-based nets induced higher mortality against pyrethroid-resistant An. funestus than pyrethroid-only nets [30]. PBO is a synergist that inhibits insecticide resistance induced by the presence of cytochrome P450 metabolic enzymes [14]. The inhibition of P450 enzymes by PBO results in increased efficacy of pyrethroids on resistant mosquito populations [51]. However, it is still difficult to conclude that the increased mortality registered between PBO-based nets and standard LLINs derives from $\mathrm{PBO}$ because the original concentration of pyrethroid or the bleed rate of pyrethroid in the pyrethroidPBO net was found to differ significantly from that in the pyrethroid-only LLINs [26, 39].

A high blood feeding inhibition (BFI) rate of over $64 \%$ was recorded and attributed to the irritant effect of pyrethroids [16]. In fact, several pyrethroids such as bifenthrin and deltamethrin are known to induce high irritancy effects on mosquito populations [15, 23, 24]. Recent studies in Cameroon with PermaNet $^{\circledR} 3.0$ and Olyset Plus [30] also recorded a high irritancy effect on An. funestus. In Benin, Olyset and Olyset Plus nets were found to induce a high BFI rate in An. gambiae [39]. The high blood feeding inhibition effect of PermaNet ${ }^{\circledR} 2.0$ nets suggests a possible influence of this tool against resistant mosquito populations.
A high exophilic rate $(57.6 \%)$ was recorded when resistant mosquitoes were exposed to PermaNet ${ }^{\circledR} 2.0$ nets. In Cote d'Ivoire and Benin, resistant mosquitoes were instead reported to exhibit a low exophily rate to permethrin, deltamethrin and bifenthrin [26, 34]. This contrasting pattern could be associated with differences in behaviour, resistance intensity, and resistance mechanisms. Importantly, An. gambiae s.l. populations from the city of Yaoundé were reported to be highly exophagic [18]. Despite a high LLIN ownership rate, it is estimated that less than $60 \%$ of the human population used bed nets properly [42]; in fact, many people stay outdoors late into the night [52]. This situation could have selected exophagic and exophilic behaviour in vector populations. Despite this, a high number of resistant mosquitoes were collected blood-fed in treated nets, confirming their ability to also take blood meals from people sleeping under treated nets. Only a quarter of blood-fed mosquitoes were found dead after a blood meal.

As reported in previous studies, the efficiency of treated nets could depend on the intensity of insecticide resistance and the diversity of detoxification resistance mechanisms. Because resistance characteristics could vary significantly from one epidemiological setting to another, comparison trials of different brands of treated bed nets should be conducted in the same locality, in order to identify nets that are particularly effective against local vector populations.

Although assessment of the washing effect on the net efficacy was not investigated in this study, previous hut trials conducted in Benin and Cote d'Ivoire indicated a significant decrease in PBO content and PBO-based net efficacy (mortality and blood feeding inhibition) after several washes, with PBO nets performing no better than pyrethroid-only LLINs $[26,35]$. Despite the decrease in PBO content on the net under natural conditions, the use of PBO-based nets was reported to induce a $33 \%$ reduction in malaria incidence in children compared to pyrethroid-only nets after 21 months [44]. Moreover, although the rapid expansion of insecticide resistance could affect pyrethroid-treated net efficacy, it is still not clear whether this is inducing sub-performance of the intervention in the city of Yaoundé. Our study highlights the need for large-scale field effectiveness studies to assess the effect of insecticide resistance on the performance of pyrethroid-treated nets in Yaoundé.

\section{Conclusion}

This study provided evidence of the limited efficacy of the standard treated bed net (PermaNet ${ }^{\circledR} 2.0$ ) against pyrethroidresistant An. coluzzii populations in the city of Yaoundé. As previously highlighted by numerous studies, the rapid expansion of insecticide resistance could seriously affect the efficiency of vector control measures implemented in the field. This situation requires the implementation of new control strategies such as the replacement of standard LLINs by PBO-based LLINs or new-generation LLINs, or the addition of new control measures such as IRS or larviciding to preserve existing tools and to manage insecticide resistance. It is urgent that new control tools, such as PBO-based nets, be included in the arsenal of tools used for malaria vector control in Cameroon. However, as done elsewhere, the adoption of this tool will require large-scale 
randomised controlled trials in order to assess the impact of the intervention on both entomological and epidemiological indicators, as recommended by the WHO [59].

\section{Abbreviations}

LLINs: Long-Lasting Insecticidal Nets; IRS: Indoor Residual Spraying; WHO: World Health Organization; PBO: piperonyl butoxide

\section{Competing interests}

The authors declare that they have no competing interests.

\section{Funding}

This work received financial support from WHO TDR grant 2016/602099-0 and a Wellcome Trust Senior Fellowship in Public Health and Tropical Medicine (202687/Z/16/Z) to CAN. The funding bodies played no role in the design of the study, collection of data, analysis and interpretation of data, nor in writing of the manuscript.

\section{Authors' contributions}

RB and CAN: conceptualised and designed the study; RB, EK, LDN, BDM, PAA, and CAN performed the field and laboratory experiments. RB performed the statistical analysis. RB, EK, LDN, BDM, PAA, TT, FN, CSW, and CAN critically reviewed and amended the manuscript. $\mathrm{RB}$ and $\mathrm{CAN}$ wrote the manuscript with input from all authors. All authors read and approved the final manuscript.

Acknowledgements. We express our gratitude to the people who participated in this study, mainly sleepers during experimental hut trials.

\section{References}

1. Akoton R, Tchigossou GM, Djègbè I, Yessoufou A, Atoyebi MS, Tossou E, Zeukeng F, Boko P, Irving H, Adéoti R, Riveron J, Wondji CS, Moutairou K, Djouaka R. 2018. Experimental huts trial of the efficacy of pyrethroids/piperonyl butoxide (PBO) net treatments for controlling multi-resistant populations of Anopheles funestus s.s. in Kpomè, Southern Benin. Wellcome Open Research, 3, 71.

2. Antonio-Nkondjio C, Ndo C, Njiokou F, Bigoga JD, AwonoAmbene P, Etang J, Same Ekobo A, Wondji CS. 2019. Review of malaria situation in Cameroon: Technical viewpoint of challenges and prospects for disease elimination. Parasites \& Vectors, 12, 501.

3. Antonio-Nkondjio C, Poupardin R, Tene BF, Kopya E, Costantini C, Awono-Ambene P, Wondji CS. 2016. Investigation of mechanisms of bendiocarb resistance in Anopheles gambiae populations from the city of Yaoundé, Cameroon. Malaria Journal, 15(1), 424.

4. Antonio-Nkondjio C, Sonhafouo-Chiana N, Ngadjeu CS, Doumbe-Belisse P, Talipouo A, Djamouko-Djonkam L, Kopya E, Bamou R, Awono-Ambene P, Wondji CS. 2017.
Review of the evolution of insecticide resistance in main malaria vectors in Cameroon from 1990 to 2017. Parasites \& Vectors, 10(1), 472.

5. Antonio-Nkondjio C, Tene Fossog B, Kopya E, Poumachu Y, Menze Djantio B, Ndo C, Tchuinkam T, Awono-Ambene P, Wondji CS. 2015. Rapid evolution of pyrethroid resistance prevalence in Anopheles gambiae populations from the cities of Douala and Yaounde (Cameroon). Malaria Journal, 14, 155.

6. Asidi A, N'Guessan R, Akogbeto M, Curtis C, Rowland M. 2012. Loss of household protection from use of insecticidetreated nets against pyrethroid-resistant mosquitoes, Benin. Emerging Infectious Diseases, 18(7), 1101-1106.

7. Balabanidou V, Grigoraki L, Vontas J. 2018. Insect cuticle: a critical determinant of insecticide resistance. Current Opinion in Insect Science, 27, 68-74.

8. Balabanidou V, Kampouraki A, MacLean M, Blomquist GJ, Tittiger C, Juárez MP, Mijailovsky SJ, Chalepakis G, Anthousi A, Lynd A, Antoine S, Hemingway J, Ranson H, Lycett GJ, Vontas J. 2016. Cytochrome P450 associated with insecticide resistance catalyzes cuticular hydrocarbon production in Anopheles gambiae. Proceedings of the National Academy of Sciences, 113(33), 9268-9273.

9. Bamou R, Mbakop LR, Kopya E, Ndo C, Awono-Ambene P, Tchuinkam T, Rono MK, Mwangangi J, Antonio-Nkondjio C. 2018. Changes in malaria vector bionomics and transmission patterns in the equatorial forest region of Cameroon between 2000 and 2017. Parasites \& Vectors, 11(1), 464.

10. Bamou R, Sonhafouo-Chiana N, Mavridis K, Tchuinkam T, Wondji CS, Vontas J, Antonio-Nkondjio C. 2019. Status of insecticide resistance and its mechanisms in Anopheles gambiae and Anopheles coluzzii populations from forest settings in south Cameroon. Genes, 10(10), 741.

11. Bass C, Nikou D, Vontas J, Williamson M, Field L. 2010. Development of high-throughput real-time PCR assays for the identification of insensitive acetylcholinesterase in Anopheles gambiae. Pesticide Biochemistry and Physiology, 96, 80-85.

12. Bayili K, N'Do S, Yadav RS, Namountougou M, Ouattara A, Dabiré RK, Ouédraogo GA, Diabaté A. 2019. Experimental hut evaluation of DawaPlus 3.0 LN and DawaPlus 4.0 LN treated with deltamethrin and PBO against free-flying populations of Anopheles gambiae s.l. in Vallée du Kou, Burkina Faso. PLoS ONE, 14(12), e0226191-e0226191.

13. Bhatt S, Weiss DJ, Cameron E, Bisanzio D, Mappin B, Dalrymple U, Battle K, Moyes CL, Henry A, Eckhoff PA, Wenger EA, Briët O, Penny MA, Smith TA, Bennett A, Yukich J, Eisele TP, Griffin JT, Fergus CA, Lynch M, Lindgren F, Cohen JM, Murray CLJ, Smith DL, Hay SI, Cibulskis RE, Gething PW. 2015. The effect of malaria control on Plasmodium falciparum in Africa between 2000 and 2015. Nature, 526 (7572), 207-211.

14. Bingham G, Strode C, Tran L, Khoa P, Jamet H. 2011. Can piperonyl butoxide enhance the efficacy of pyrethroids against pyrethroid-resistant Aedes aegypti? Tropical Medicine and International Health, 16(4), 492-500.

15. Chouaibou M, Simard F, Chandre F, Etang J, Darriet F, Hougard J. 2006. Efficacy of bifenthrin-impregnated bed nets against Anopheles funestus and pyrethroid-resistant Anopheles gambiae in North Cameroon. Malaria Journal, 5, 77.

16. Darriet F, Hougard J, Corbel V. 2005. Comportement d'Anopheles gambiae $\mathrm{kdr}+$ face a des moustiquaires biimpregnées d'insecticides pyrethrinoïde et organophosphoré. Bulletin de la Société de Pathologie Exotique, 98, 201-204.

17. Djènontin A, Ahoua Alou LP, Koffi A, Zogo B, Duarte E, N'Guessan R, Moiroux N, Pennetier C. 2015. Insecticidal and sterilizing effect of Olyset Duo ${ }^{\circledR}$, a permethrin and pyriproxyfen mixture net against pyrethroid-susceptible and -resistant strains 
of Anopheles gambiae s.s.: a release-recapture assay in experimental huts. Parasite, 22, 27.

18. Doumbe-Belisse P, Ngadjeu CS, Sonhafouo-Chiana N, Talipouo A, Djamouko-Djonkam L, Kopya E, Bamou R, Toto JC, Mounchili S, Tabue R, Awono-Ambene P, Wondji CS, Njiokou F, Antonio-Nkondjio C. 2018. High malaria transmission sustained by Anopheles gambiae sl occurring both indoors and outdoors in the city of Yaoundé, Cameroon. Wellcome Open Research, 3, 164.

19. Elanga-Ndille E, Nouage L, Ndo C, Binyang A, Assatse T, Nguiffo-Nguete D, Djonabaye D, Irving H, Tene-Fossog B, Wondji CS. 2019. The G119S acetylcholinesterase (Ace-1) target site mutation confers carbamate resistance in the major malaria vector Anopheles gambiae from Cameroon: A challenge for the coming IRS Implementation. Genes, 10(10), 790.

20. Etang J, Chandre F, Guillet P, Manga L. 2004. Reduced bio-efficacy of permethrin EC impregnated bednets against an Anopheles gambiae strain with oxidase-based pyrethroid tolerance. Malaria Journal, 3, 46.

21. Gillies M, Coetzee M. 1987. A supplement to the Anophelinae of Africa south of the Sahara (Afrotropical region). Publication of the South African Institute of Medical Research Johannesburg., $143 \mathrm{p}$.

22. Gillies M, De Meillon B. 1968. The Anophelinae of Africa South of the Sahara. South Africa Institute of Medical Research Johannesburg, $343 \mathrm{p}$.

23. Hougard J, Corbel V, N'Guessan R, Darriet F, Chandre F, Akogbeto M, Baldet T, Guillet P, Carnevale P, Traore-Lamizana M. 2003. Efficacy of mosquito nets treated with insecticide mixtures or mosaics against insecticide resistant Anopheles gambiae and Culex quinquefasciatus (Diptera: Culicidae) in Cote d'Ivoire. Bulletin of Entomology Research, 93, 491-498.

24. Hougard JM, Duchon S, Zaim M, Guillet P. 2002. Bifenthrin: a useful pyrethroid insecticide for treatment of mosquito nets. Journal of Medical Entomology, 339(3), 526-533.

25. Killeen GF. 2014. Characterizing, controlling and eliminating residual malaria transmission. Malaria Journal, 13, 330.

26. Koudou B, Koffi A, Malone D, Hemingway J. 2011. Efficacy of PermaNet 2.0 and PermaNet 3.0 against insecticide-resistant Anopheles gambiae in experimental huts in Cote d'Ivoire. Malaria Journal, 10, 172.

27. Kweka EJ, Lyaruu LJ, Mahande AM. 2017. Efficacy of PermaNet $^{\circledR} 3.0$ and PermaNet ${ }^{\circledR} 2.0$ nets against laboratoryreared and wild Anopheles gambiae sensu lato populations in northern Tanzania. Infectious Diseases of Poverty, 6(1), 11.

28. Mahande AM, Msangi S, Lyaruu LJ, Kweka EJ. 2018. Bioefficacy of DuraNet ${ }^{\circledR}$ long-lasting insecticidal nets against wild populations of Anopheles arabiensis in experimental huts. Tropical Medicine and Health, 46(1), 1-8.

29. Mavridis K, Wipf N, Medves S, Erquiaga I, Müller P, Vontas J. 2019. Rapid multiplex gene expression assays for monitoring metabolic resistance in the major malaria vector Anopheles gambiae. Parasites \& Vectors, 12(1), 9.

30. Menze BD, Kouamo MF, Wondji MJ, Tchapga W, Tchoupo M, Kusimo MO, Mouhamadou CS, Riveron JM, Wondji CS. 2020. An experimental hut evaluation of PBO-Based and pyrethroidonly nets against the malaria vector Anopheles funestus reveals a loss of bed nets efficacy associated with GSTe2 metabolic resistance. Genes, 11(2), 143.

31. Moiroux N, Gomez M, Pennetier C, Elanga E, Djenontin A, Chandre F, Guis H, Corbel V. 2012. Changes in Anopheles funestus biting behavior following universal coverage of longlasting insecticidal nets in Benin. Journal of Infectious Diseases, 206(10), 1622-1629.

32. Mugenzi LM, Menze BD, Tchouakui M, Wondji MJ, Irving H, Tchoupo M, Hearn J, Weedall GD, Riveron JM, Wondji CS.
2019. Cis-regulatory CYP6P9b P450 variants associated with loss of insecticide-treated bed net efficacy against Anopheles funestus. Nature communications, 10(1), 1-11.

33. Mwangangi JM, Mbogo CM, Orindi BO, Muturi EJ, Midega JT, Nzovu J, Gatakaa H, Githure J, Borgemeister C, Keating J, Beier JC. 2013. Shifts in malaria vector species composition and transmission dynamics along the Kenyan coast over the past 20 years. Malaria Journal, 12, 13.

34. N'Guessan R, Corbel V, Akogbeto M, Rowland M. 2007. Reduced efficacy of insecticide-treated nets and indoor residual spraying for malaria control in pyrethroid resistance area, Benin. Emerging Infectious Diseases, 13, 199-206.

35. N'Guessan R, Asidi A, Boko P, Odjo A, Akogbeto M, Pigeon O, Rowland M. 2010. An experimental hut evaluation of PermaNet ${ }^{\circledR}$ 3.0, a deltamethrin-piperonyl butoxide combination net, against pyrethroid-resistant Anopheles gambiae and Culex quinquefasciatus mosquitoes in southern Benin. Transaction of the Royal Society of Tropical medecine and. Hygiene, 104(12), 758-765.

36. Ochomo E, Bayoh N, Walker E, Abongo B, Ombok M, Ouma C, Githeko A, Vulule J, Yan G, Gimnig J. 2013. The efficacy of long-lasting nets with declining physical integrity may be compromised in areas with high levels of pyrethroid resistance. Malaria Journal, 12(1), 368.

37. Okumu FO, Mbeyela E, Lingamba G, Moore J, Ntamatungiro AJ, Kavishe DR, Kenward MG, Turner E, Lorenz LM, Moore SJ. 2013. Comparative evaluation of combinations of longlasting insecticidal nets and indoor residual spraying, relative to either method alone, for malaria vector control in an area dominated by Anopheles arabiensis. Parasites \& Vectors, 6, 46.

38. Oumbouke WA, Koffi AA, Alou LPA, Rowland M, N'Guessan R. 2019. Evaluation of standard pyrethroid based LNs (MiraNet and MagNet) in experimental huts against pyrethroid resistant Anopheles gambiae sl M'bé, Côte d'Ivoire: Potential for impact on vectorial capacity. PLoS ONE, 14(4), e0215074.

39. Pennetier C, Bouraima A, Chandre F, Piameu M, Etang J, Rossignol M, Sidick I, Zogo B, Lacroix M, Yadav R, Pigeon O, Corbel V. 2013. Efficacy of Olyset plus a new long lasting insecticide net incorporating permethrin and piperonil-butoxide against multi-resistant malaria vectors. PLoS One, 8, e75134.

40. Pfaffl M. 2001. A new mathematical model for relative quantification in real-time RT-PCR. Nucleic Acids Research, 29, 45.

41. Philbert A, Lyantagaye SL, Nkwengulila G. 2014. A review of agricultural pesticides use and the selection for resistance to insecticides in malaria vectors. Advances in Entomology, 2, 120-128.

42. PNLP. 2018. Rapport de mise en œuvre du Programme national de lutte contre le paludisme du Cameroun. Ministère de la santé: Yaoundé. p. 47p.

43. PNLP. 2019. Plan Stratégique National de Lutte contre le Paludisme au Cameroun 2019. Rapport Minsante Cameroun Yaoundé, $125 \mathrm{p}$.

44. Protopopoff N, Mosha JF, Lukole E, Charlwood JD, Wright A, Mwalimu CD, Manjurano A, Mosha FW, Kisinza W, Kleinschmidt I, Rowland M. 2018. Effectiveness of a longlasting piperonyl butoxide-treated insecticidal net and indoor residual spray interventions, separately and together, against malaria transmitted by pyrethroid-resistant mosquitoes: a cluster, randomised controlled, two-by-two factorial design trial. Lancet, 391(10130), 1577-1588.

45. Randriamaherijaona S, Briët OJT, Boyer S, Bouraima A, N'Guessan R, Rogier C, Corbel V. 2015. Do holes in long-lasting insecticidal nets compromise their efficacy against pyrethroid resistant Anopheles gambiae and Culex quinquefasciatus? Results from a release-recapture study in experimental huts. Malaria Journal, 14, 332.

46. Riveron JM, Watsenga F, Irving H, Irish SR, Wondji CS. 2018. High Plasmodium infection rate and reduced bed net efficacy in 
multiple insecticide-resistant malaria vectors in Kinshasa, Democratic Republic of Congo. Journal of Infectious Diseases, 217(2), 320-328.

47. Riveron JM, Yunta C, Ibrahim SS, Djouaka R, Irving H, Menze BD, Ismail HM, Hemingway J, Ranson H, Albert A, Wondji CS. 2014. A single mutation in the GSTe2 gene allows tracking of metabolically based insecticide resistance in a major malaria vector. Genome Biology, 15(2), R27.

48. Russell T, Govella N, Azizi S, Drakeley C, Kachur S, Killeen G. 2011. Increased proportions of outdoor feeding among residual malaria vector populations following increased use of insecticide-treated nets in rural Tanzania. Malaria Journal, 10, 80.

49. Santolamazza F, Mancini E, Simard F, Qi Y, Tu Z. 2008. Insertion polymorphisms of SINE200 retrotransposons within speciation islands of Anopheles gambiae molecular forms. Malaria Journal, 7, 163.

50. Simma AE, Dermauw W, Balabanidou V, Snoeck S, Bryon A, Clark R, Yewhalaw D, Vontas J, Duchateau L, Van Leeuwen T. 2019. Genome-wide gene expression profiling reveals that cuticle alterations and P450 detoxification are associated with deltamethrin and DDT resistance in Anopheles arabiensis populations from Ethiopia. Pest Management Science, 75(7), 1808-1818.

51. Stevenson B, Bibby J, Pignatelli $\mathrm{P}$, Muangnoicharoen $\mathrm{S}$, O'Neill P, Lian L, Muller P, Nikou D, Steven A, Hemingway J, Sutcliffe M, Paine M. 2011. Cytochrome P450 6 M2 from the malaria vector Anopheles gambiae metabolizes pyrethroids: sequential metabolism of deltamethrin revealed. Insect Biochemistry andMolecular Biology, 41(7), 492-502.

52. Talipouo A, Ngadjeu CS, Doumbe-Belisse P, DjamoukoDjonkam L, Sonhafouo-Chiana N, Kopya E, Bamou R, Awono-Ambene P, Woromogo S, Kekeunou S, Wondji CS, Antonio-Nkondjio C. 2019. Malaria prevention in the city of Yaoundé: knowledge and practices of urban dwellers. Malaria Journal, 18(1), 167.

53. Tene Fossog B, Poupardin R, Costantini C, Awono-Ambene H, Wondji C, Ranson H, Antonio-Nkondjio C. 2013. Resistance to DDT in an urban setting: common mechanisms implicated in both $\mathrm{M}$ and $\mathrm{S}$ forms of Anopheles gambiae in the city of Yaoundé Cameroon. PLoS ONE, 8, e61408.

54. Tungu P, Magesa S, Maxwell C, Malima R, Masue D, Sudi W, Myamba J, Pigeon O, Rowland M. 2010. Evaluation of
PermaNet 3.0 a deltamethrin-PBO combination net against Anopheles gambiae and pyrethroid-resistant Culex quinquefasciatus mosquitoes: an experimental hut trial in Tanzania. Malaria Journal, 9, 21.

55. Weedall GD, Mugenzi LMJ, Menze BD, Tchouakui M, Ibrahim SS, Amvongo-Adjia N, Irving $\mathrm{H}$, Wondji MJ, Tchoupo M, Djouaka R, Riveron JM, Wondji CS. 2019. A cytochrome P450 allele confers pyrethroid resistance on a major African malaria vector, reducing insecticide-treated bednet efficacy. Science Translational Medicine, 11, 484.

56. WHO. 2013. World Malaria Report Geneva. World Health Organization. WHO Press: Geneva. p. 17

57. WHO. 2013. Guidelines for laboratory and field testing of longlasting insecticidal nets. World Health Organization WHO/ HTM/NTD/WHOPES/2013. World Health Organization. WHO Press: Geneva, $73 \mathrm{p}$.

58. WHO. 2016. Test procedures for insecticide resistance monitoring in malaria vector mosquitoes. WHO Press: Geneva. p. 43.

59. WHO. 2018. World Malaria Report 2018. World Health Organization, 2018. Licence: CC BY-NC-SA 3.0 IGO. WHO Press: Geneva. p. 65.

60. WHO. 2020. World Malaria Report. Geneva, 20 years of global progress and challenges World Health Organization; 2020. Licence CC BY-NC-SA 3.0 IGO. WHO Press: Geneva. p. 123. https://creativecommons.org/licence/by-nc-sa/3.0/igo.

61. Wondji 6CS, Irving H, Morgan J, Lobo NF, Collins FC, Hunt RH, Coetzee M, Hemingway J, Hilary R. 2009. Two duplicated P450 genes are associated with pyrethroid resistance in Anopheles funestus, a major malaria vector. Genome Research, 19(3), 452-459.

62. Yadouleton A, Asidi A, Djouaka R, Braima J, Agossou C, Akogbeto M. 2009. Development of vegetable farming: a cause of the emergence of insecticide resistance in populations of Anopheles gambiae in urban areas of Benin. Malaria Journal, 8, 103.

63. Yahouédo GA, Chandre F, Rossignol M, Ginibre C, Balabanidou V, Mendez NGA, Pigeon O, Vontas J, Cornelie S. 2017. Contributions of cuticle permeability and enzyme detoxification to pyrethroid resistance in the major malaria vector Anopheles gambiae. Scientific Reports, 7(1), 11091.

Cite this article as: Bamou R, Kopya E, Nkahe LD, Menze BD, Awono-Ambene P, Tchuinkam T, Njiokou F, Wondji CS \& AntonioNkondjio C. 2021. Increased prevalence of insecticide resistance in Anopheles coluzzii populations in the city of Yaoundé, Cameroon and influence on pyrethroid-only treated bed net efficacy. Parasite 28, 8 .

Reviews, articles and short notes may be submitted. Fields include, but are not limited to: general, medical and veterinary parasitology; morphology, including ultrastructure; parasite systematics, including entomology, acarology, helminthology and protistology, and molecular analyses; molecular biology and biochemistry; immunology of parasitic diseases; host-parasite relationships; ecology and life history of parasites; epidemiology; therapeutics; new diagnostic tools.

All papers in Parasite are published in English. Manuscripts should have a broad interest and must not have been published or submitted elsewhere. No limit is imposed on the length of manuscripts.

Parasite (open-access) continues Parasite (print and online editions, 1994-2012) and Annales de Parasitologie Humaine et Comparée (1923-1993) and is the official journal of the Société Française de Parasitologie. 